\title{
Influence of laser powder bed fusion process conditions and resulting microstructures on the electromagnetic properties of a $16 \mathrm{MnCr} 5$ steel
}

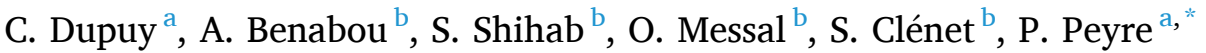 \\ ${ }^{a}$ PIMM, Arts et Metiers Institute of technology, CNRS, CNAM, HESAM University, 151 Bd de l'Hopital, 75013 Paris, France \\ ${ }^{\mathrm{b}}$ University Lille, Arts et Metiers Institute of Technology, Centrale Lille, Yncrea Hauts-de-France, ULR 2697 - L2EP, F-59000 Lille, France
}

Keywords:

L-PBF

Powder bed

Laser

$16 \mathrm{MnCr} 5$

Steel

Magnetic

\begin{abstract}
A B S T R A C T
$16 \mathrm{MnCr} 5$ steel parts were additively manufactured by laser powder bed fusion in order to investigate the effect of microstructure on electromagnetic properties. As process parameters have a direct impact on the obtained microstructure, different conditions were used to manufacture samples on which magnetic and electrical tests were conducted. The obtained results were presented and discussed in terms of density, microstructure and electromagnetic properties. Finally, correlations have been demonstrated between the microstructure and the electromagnetic performances. Lower magnetic and electric properties were obtained with the higher porosity rates at low volume energy density. The microstructural effects were evidenced, through a decrease in magnetic properties with grain orientation, and an improvement with stress relief annealing.
\end{abstract}

\section{Introduction}

Laser powder bed fusion (L-PBF) of metal parts is increasingly used in several industrial fields like medical, aeronautical or tooling. It allows building complex and precise metallic components, which are not directly achievable by conventional methods and can provide similar or better mechanical properties than casting or forging. Current limitations of the L-PBF process come from:

(1) the supporting structures, considered to be mandatory for the overhanging surfaces above a given threshold angle (usually near $45^{\circ}$ ) and hard to remove [1],

(2) the rather deleterious surface finish $\left(R_{a}>5 \mu \mathrm{m}\right)$, compared to asmachined surfaces due to powder agglomerates and staircase effect [2].

(3) the occurrence of residual porosities - usually less than $0.5 \%$ for optimized process conditions - that can impact fatigue properties [3].

A number of previous studies have shown that parts processed by LPBF have anisotropic characteristics due to grain orientations and growth morphology as shown by Andreau et al. [3]. Due to the mechanisms of grain re-melting and epitaxial growth during the laser-induced melting-solidification procedures, the grain texture of cubic crystals are often oriented according to the crystallographic axis $\langle 001\rangle$ or $\langle 011\rangle$. The microstructural anisotropy is strongly affected by both the laser energy input density and the laser scan strategy as indicated by [4]. Also, the high cooling $\left(10^{5}-10^{7} \mathrm{~K} / \mathrm{s}\right)$ and solidification rates $(0.1-1 \mathrm{~m} / \mathrm{s})$ generate a fine cellular microstructure (cell size of the order of $1 \mu \mathrm{m}$ ) and strong chemical intercellular segregation. Most of L-PBF materials exhibit, in the optimized state, $0.01-0.5 \%$ of porosities (lacks-of-fusion or blowholes) with sizes ranging between $0.5 \mu \mathrm{m}$ and $30 \mu \mathrm{m}$. Yan et al. have shown that L-PBF materials also contain a high dislocation density (around $10^{15} \mathrm{~m}^{-2}$ ) originating from the rapid contraction of liquid metal and localized near the intercellular spaces [5], which often makes the material recrystallizable during post-L-PBF annealing as shown by Kreitcberg et al. on a nickel-based superalloy [6].

Most of the published researches on metal alloys used in AM, deal with their mechanical properties, as indicated in the 2014's review by Frazier [7], but only few bibliographic data are available about their electromagnetic properties. Metallurgical parameters are expected to strongly impact the electromagnetic properties of L-PBF manufactured pieces by impeding the magnetic domain-wall movement and changing their structuration. Intrinsic parameters such as the chemical composition can modify the different magnetic energy terms or the electrical conductivity, while extrinsic parameters such as the crystallographic texture, grain sizes, defects or residual stresses can modify the magnetic domain structure or cause domain wall pinning and act as a source of coercivity. The result can have dramatic impact on the material

\footnotetext{
* Corresponding author.

E-mail address: patrice.peyre@ensam.eu (P. Peyre).
} 
performance working for example under a $50 \mathrm{~Hz}$ cyclic magnetic field of a sinusoidal waveform, with an increase in their magnetic losses and a decrease in their magnetic relative permeability, as indicated by Everhart et al. [8].

Some authors investigated the impact of L-PBF processes on magnetic properties. Hilzinger and Rodewald [9] compared the composition, phase and magnetic properties of a wrought $\mathrm{Fe}-\mathrm{Co}-2 \mathrm{~V}$ alloy to the $\mathrm{AM}$ version with and without heat treatment. They both exhibit a significant improvement of magnetic properties with an ordering heat treatment $\left(2 \times 900{ }^{\circ} \mathrm{C}, 2 \mathrm{~h}\right)$. However, L-PBF samples had smaller grain sizes that resulted in higher yield strength and magnetic coercivity, i.e., higher iron losses. Different post-L-PBF heat treatments were also conducted by Riipinen et al. [10]. One of them (pre-annealing $700{ }^{\circ} \mathrm{C}, 2 \mathrm{~h}$ then $820^{\circ} \mathrm{C}, 10 \mathrm{~h}$ ) improved the magnetic properties of iron-cobalt soft magnetic alloys (Fe-49Co-2V). Yakout et al. [11] compared the density, microstructure, magnetic and electrical properties of L-PBF built motor stators produced from soft magnetic alloys (430 L, Fe5-O-Ni, Fe6-Si) with that of an original motor with laminations and isolators. Only Fe5-O-Ni and $430 \mathrm{~L}$ samples were tested, as cracks appeared on the Fe6-Si sample. The electrical resistance of the L-PBF motors were in line with that of the original laminated motor but their inductance was lower due to poorer magnetic properties. Recently, Li et al. [12] studied the effect of the microstructure of annealed L-PBF samples (Ni-15Fe-5Mo) on their mechanical and magnetic properties. A magnetic anisotropy was observed, the better results being obtained when the magnetic induction was parallel to the building direction. The obtained saturation magnetization value was equivalent to conventionally processed samples but the coercivity was higher.

Garibaldi et al. $[13,14]$ focused their work on the FeSi $6.9 \%$, a material with practical importance in electrical engineering due to its lower electrical conductivity (i.e., high electrical resistivity) compared to the more common FeSi 3\%, as well as lower magnetostriction coefficient. Considering ring samples, the authors investigated the effect on magnetic properties of (1) post L-PBF annealing up to $1200^{\circ} \mathrm{C}$ [13], (2) scan strategy and laser energy input [14], and correlated the variation of magnetic properties with the grain size and presence of B2/DO3 phase and texture orientation. For the same material, Goll et al. [15] evaluated the impact of laser input energy and a $1 \mathrm{~h}-1150{ }^{\circ} \mathrm{C}$ heat treatment on magnetic losses at $50 \mathrm{~Hz}$ and correlated the observed variations with the porosity rate and the occurrence of cracks in the material.

Otherwise, due to the high thickness of L-PBF parts, eddy-current losses can constitute a significant part of the magnetic losses at a given working frequency. To reduce these losses, Goll [15] and Plotkowski et al. [16] studied the impact of more complex topological core structures on electromagnetic losses. Plotkowski et al. showed that the electromagnetic losses can be decreased by a factor 20 depending on the filling strategy. Among the tested configurations, the thin wall samples based on Hilbert filling pattern demonstrated the best performances.

Finally, building magnetic materials by L-PBF presents additional difficulties compared to mechanical parts and requires specific optimization criteria, due to clear dependence of magnetic properties on the induced microstructure. However, there is a growing interest of the industry for the L-PBF manufacturing of magnetic parts, especially when the soft magnetic piece cannot be produced by cold rolling or when the application requires non-laminated magnetic core.

In this study, the feasibility of manufacturing $16 \mathrm{MnCr} 5$ (1.7131) ferromagnetic components by L-PBF is investigated. $16 \mathrm{MnCr} 5$ is a case hardened steel mostly used in gear applications, and containing approximately $0.15 \%$ C. On the same material, Schmitt et al. $[17,18]$ have recently indicated a rather good L-PBF processability with more than $99.5 \%$ density of built parts [17] and up to $99.9 \%$ in their more recent work. The same authors also investigated the influence of post-L-PBF heat treatments on L-PBF gears [18]. Prior to case hardening, they recommend a recrystallization annealing after L-PBF to provide a large stress relief, a better mechanical isotropy and to favour machining.

Bartels [19] also manufactured $16 \mathrm{MnCr} 5$ steel with L-PBF with the objective of optimizing hardness distribution after case hardening. The resulting observed effect was an increase of both hardness level and depth for L-PBF + case hardening samples compared with classical manufacturing processes. This was supposed to be due to the fine grains in the L-PBF material. Therefore, our work was focused on the effects of processing conditions on the microstructure and resulting electrical and magnetic properties of $16 \mathrm{MnCr} 5$.

\section{Experimental details}

\subsection{Material}

The $16 \mathrm{MnCr} 5$ steel (composition given in Table 1 ) is a cementation steel used for parts requiring a combination of hardness and wear resistance such as gears, shafts and steering parts in mechanical engineering. Due to its ferromagnetic properties, it is also envisaged for combined magnetic - mechanical applications. For instance, in [20], this material is employed in the study of an electromagnetic high-speed solenoid valve for common rail injector.

The material used for L-PBF experiments was a gas-atomized $16 \mathrm{MnCr} 5$ steel powder supplied by TLS Technik. To obtain the desired range of powder diameters, the powder was sieved to limit the maximum diameter to $63 \mu \mathrm{m}$. The resulting particle size distribution was $d_{10}=15 \mu \mathrm{m}, d_{50}=30 \mu \mathrm{m}, d_{90}=48 \mu \mathrm{m}$, and an average size of approximately $35 \mu \mathrm{m}$. The particles had a spherical morphology, with a few agglomerated satellites (see Fig. 1).

\section{2. $L$-PBF experiments}

A SLM125HL machine, from SLM solutions ${ }^{\mathrm{GmbH}}$ was used to print the samples. The machine is equipped with a f420 F-Theta lens and a scanning head which ensures the movement of the beam on the surface of the powder. The used laser is a diode pumped fiber laser of IPG Photonics, with a maximum output power of $400 \mathrm{~W}$, and $1070 \mathrm{~nm}$ wavelength. Prior to L-PBF processing, the build chamber is inerted under Argon to limit the $\mathrm{O}_{2}$ rate to less than $500 \mathrm{ppm}$.

Two sets of parameters were used as shown in Table 2: one corresponding to the parameters recommended by the manufacturer, and the other one at a lower output volume energy density (VED) to evaluate the impact of defects such as pores on the magnetic and electric properties. As a reminder, the VED is calculated using (Eq. (1)). The velocity, the manufacturing strategy (number of contours, lasing strategy and scheme, focusing position) and the layer thickness remained the same. The layer thickness (= slicing distance) was $30 \mu \mathrm{m}$.

$\mathrm{VED}=\frac{P_{0}}{\left(V_{0} \cdot h d \cdot \Delta h\right)}$

with VED $\left(\mathrm{J} / \mathrm{mm}^{3}\right)=$ volume energy density, $P_{0}(\mathrm{~W})=$ laser power, $V_{0}$ $(\mathrm{mm} / \mathrm{s})=$ scan speed, $\mathrm{hd}=$ hatch distance $(\mathrm{mm}), \Delta \mathrm{h}=$ layer height (mm).

Two dimensions of toroid, both of $4 \mathrm{~mm}$ height, were built to analyze magnetic properties:

(1) $38 \mathrm{~mm}$ inner diameter/44 $\mathrm{mm}$ outer diameter (small samples "S").

(2) $50 \mathrm{~mm}$ inner diameter/60 $\mathrm{mm}$ outer diameter (large samples "L").

Some samples were built parallel to the $(x, y)$ building plane (flat

Table 1

Chemical composition of $16 \mathrm{MnCr} 5$ steel (supplier data).

\begin{tabular}{llllll}
\hline Element & $\mathrm{C}$ & $\mathrm{Si}$ & $\mathrm{Cr}$ & $\mathrm{Mn}$ & $\mathrm{S}$ \\
\hline $\mathrm{wt} \%$ & 0.17 & 0.19 & 1.1 & 1.3 & 0.02 \\
\hline
\end{tabular}



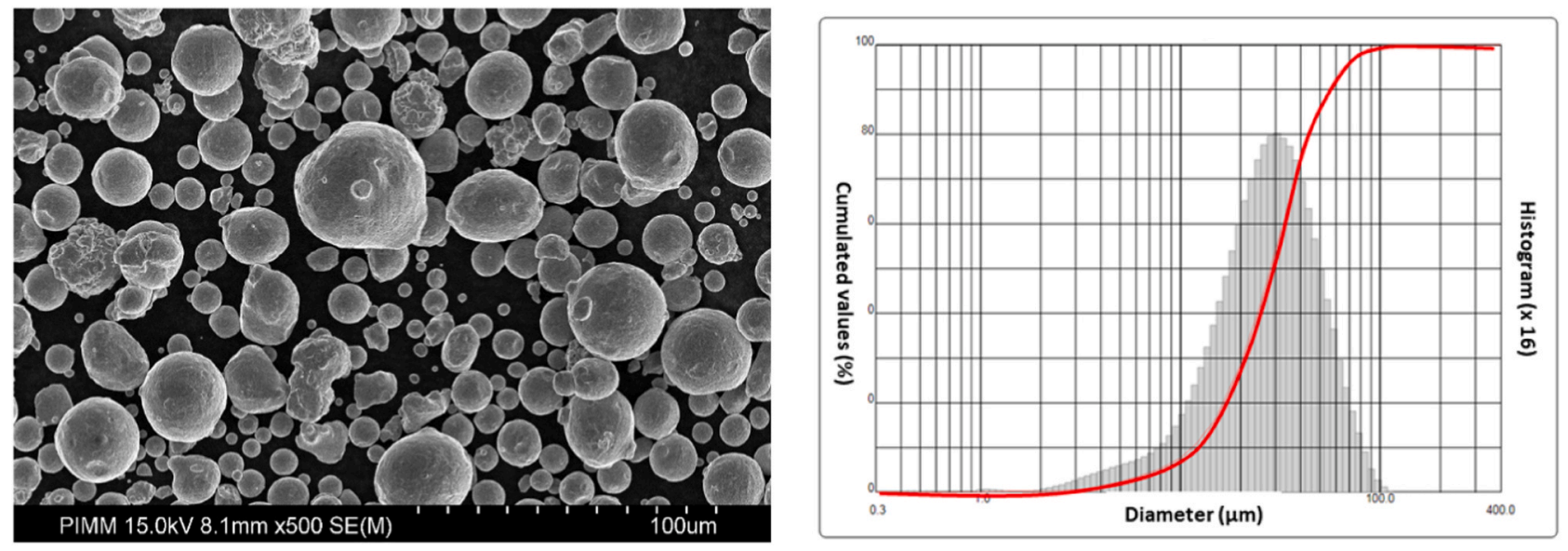

Fig. 1. (a) SEM image of $16 \mathrm{MnCr} 5$ starting powder, (b) grain distribution.

Table 2

Manufacturing parameters.

\begin{tabular}{llllll}
\hline Samples & $\begin{array}{l}\mathrm{P} \\
(\mathrm{W})\end{array}$ & $\begin{array}{l}\mathrm{V} \\
(\mathrm{mm} / \\
\mathrm{s})\end{array}$ & $\begin{array}{l}\text { hatch } \\
(\mu \mathrm{m})\end{array}$ & $\begin{array}{l}\text { Spot } \\
\text { diameter } \\
(\mu \mathrm{m})\end{array}$ & $\begin{array}{l}\text { Volume } \\
\text { Energy } \\
\text { Density }(\mathrm{J} / \\
\left.\mathrm{mm}^{3}\right)\end{array}$ \\
\hline $\begin{array}{l}\text { Bars: 3H, 2V } \\
\text { Toroids: 2 LF, 2 LT, 2 } \\
\text { SF, 2 ST }\end{array}$ & 175 & 720 & 120 & 73 & 67.5 \\
$\begin{array}{l}\text { (LF }=\text { Large Flat, } \\
\text { LT }=\text { Large Tilted, }\end{array}$ & & & & & \\
SF = Small Flat, & & & & & \\
ST $=$ Small Tilted) & & & & & \\
Bars: 3H, 3V & 150 & 720 & 140 & 73 & \\
Toroids: 2 SF, 2 LF & & & & & \\
\hline
\end{tabular}

samples "F") and some tilted at $25^{\circ}$ with respect to the $(x, y)$ plane (tilted samples "T") to check the effect of the grain growth direction on the material properties.

Bars $\left(5 \times 3 \times 30 \mathrm{~mm}^{3}\right)$ for electrical conductivity measurements were also built in two directions, parallel to the $(x, y)$ plane (samples $\mathrm{H}$ ) and vertically, along the $\mathrm{z}$ axis (samples V), as depicted in Fig. 2 .

\section{Small Tilted toroids (ST) Vertical bars (V)}

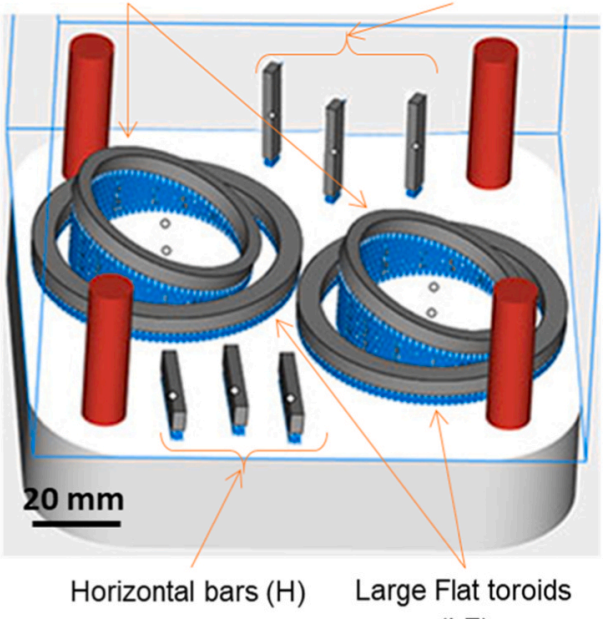

(LF)

Fig. 2. Location of samples on a building plate.

\subsection{Density measurements}

The Archimedes' method was used on the smallest samples (bars) to evaluate the density of as-built parts. The measurements were performed using a Mettler Toledo MS104TS hydrostatic weighing system equipped with a MS-DNY-43 solid sample weighing module.

This technique, based on Archimedes' principle enables to determine the volume of the samples, and their density. Samples were weighed in air atmosphere and in demineralized water at room temperature (RT). This procedure was carried out five times, with at least 30 min air drying between consecutive tests, in order to provide similar wettability conditions. The density of the samples was calculated using (Eq. (2)) from the mass obtained in each of the conditions and the density of the fluids at RT. The comparison of the results obtained with the theoretical density enables to calculate the porosity rate. The reference density $\rho_{\text {dense }}$ of the dense $16 \mathrm{MnCr} 5$ steel was set to $7.9 \mathrm{~g} / \mathrm{cm}^{3}$ as reported on the material datasheet. Demineralized water density $\rho_{\text {fluid }}$ was set (at $21.5^{\circ} \mathrm{C}$ ) to $0.9979 \mathrm{~g} / \mathrm{cm}^{3}$ and air density $\rho_{\text {air }}$ at $0.0012 \mathrm{~g} / \mathrm{cm}^{3}$.

$\rho_{\text {sample }}=\frac{M_{\text {air }}}{\left(M_{\text {air }}-M_{\text {fluid }}\right)} \times\left(\rho_{\text {fluid }}-\rho_{\text {air }}\right)+\rho_{\text {air }}$

with $\rho_{\text {sample }}=$ density of the analyzed sample $\left(\mathrm{g} \mathrm{cm}^{-3}\right), \mathrm{M}_{\text {air }}=$ weight of the sample in the air $(\mathrm{g}), \mathrm{M}_{\text {fluid }}=$ weight of the samples in the fluid $(\mathrm{g})$, $\rho_{\text {fluid }}=$ fluid density $\left(\mathrm{g} \mathrm{cm}^{-3}\right)$, $\rho_{\text {air }}=$ air density $\left(\mathrm{g} \mathrm{cm}^{-3}\right)$.

In order to analyze the porosity rate of the larger toroid samples, optical micrographs (magnification $\times 100$ ) were also performed, using a ZEISS Axio Imager optical microscope at $\times 100$ and $\times 500$ magnifications. The obtained $\times 500$ images were then binarized using the same luminosity threshold and analyzed using ImageJ software. 20 images were taken on each cross section representing approximately $10 \%$ each of the total cross-section at $\times 500$ magnification $(2452 \times 2056$ pixels $=0.34 \mathrm{~mm} \times 0.29 \mathrm{~mm}=0.097 \mathrm{~mm}^{2}$ for each image).

\subsection{Magnetic measurements}

In energy conversion devices, the relevant magnetic properties are the magnetic permeability represented by the non-linear B-H curve and the iron losses linked to the area of the magnetic hysteresis loop. In practice, the magnetic permeability represents the capability of the device to amplify the magnetic flux, which is directly linked to the volume energy density involved in the energy conversion process, whereas the iron losses represent the energy dissipation during this process. Therefore, performances in terms of magnetic properties are obtained when higher magnetic permeability (slope of the B-H curve) and lower iron losses are exhibited by the material.

To characterize the magnetic properties, the ring core technique 
(flux-metric method) is applied to the toroids presented in Section 2.2. The measurements have been realized on the MPG200D equipment from Brockhaus Measurements ${ }^{\mathrm{GmbH}}$ in accordance with the IEC 60404-4 standard [21]. The equipment exhibits a repeatability of the measurements less than $0.1 \%$.

To magnetize the magnetic core and measure the magnetic flux density, a primary coil and a secondary coil are wound on the magnetic core with respectively $N_{1}$ and $N_{2}$ turns. From the measure of the primary electrical current $I_{1}(t)$ and secondary induced voltage $V_{2}(t)$, the excitation magnetic field $H(\mathrm{~A} / \mathrm{m})$ and magnetic flux density $B(\mathrm{~T})$ are respectively calculated:

$H(t)=\frac{N_{1} I_{1}(t)}{l}$

$B(t)=\frac{1}{N_{2} S} \int V_{2}(t) d t$

where $l$ and $S$ are respectively the average magnetic path length and the cross section of the considered ring core. Finally, the relevant physical characteristic is the $B(H)$ magnetic hysteresis loop which represents the magnetic core properties. The measurements were performed at RT $\left(\sim 20^{\circ} \mathrm{C}\right)$, for each ring core, at several magnitudes of magnetic flux density up to the magnetic saturation with controlled sinusoidal magnetic flux.

For the magnetic analyzes, we will consider first the normal B-H curves, obtained from the extrema $B_{\max }\left(H_{\max }\right)$ of the measured hysteresis loops (see Fig. 3-left) and second, the iron losses which are obtained from the areas of the hysteresis loops (energy dissipation during the magnetization process). From the normal curve, we can also deduce the relative magnetic permeability $\mu_{r}(H)=B /\left(\mu_{0} H\right)$ (see Fig. 3-right) where $\mu_{0}$ is the vacuum magnetic permeability. From the hysteresis loops, two specific points can be defined (Fig. 3-left): the coercive field $H_{c}$ when $B$ $=0$ and the remanent magnetic flux density when $H=0$.

The classical approach for iron loss decomposition proposed by Bertotti [22] consists in separating into three contributions the underlying physical mechanisms such that the total losses $P_{\text {tot }}$ can be written as:

$P_{t o t}=P_{h}+P_{c l}+P_{e x c}$

where $P_{h}, P_{c l}$ and $P_{\text {exc }}$ are, respectively, the hysteresis losses, classical losses (macroscopic eddy currents) and excess losses. For a sinusoidal magnetic flux density, these contributions may be expressed as:

$P_{\text {tot }}=k_{h} f B_{\max }^{\alpha}+k_{c l} f^{2} B_{\text {max }}^{2}+k_{\text {exc }} f^{3 / 2} B_{\max }^{3 / 2}$

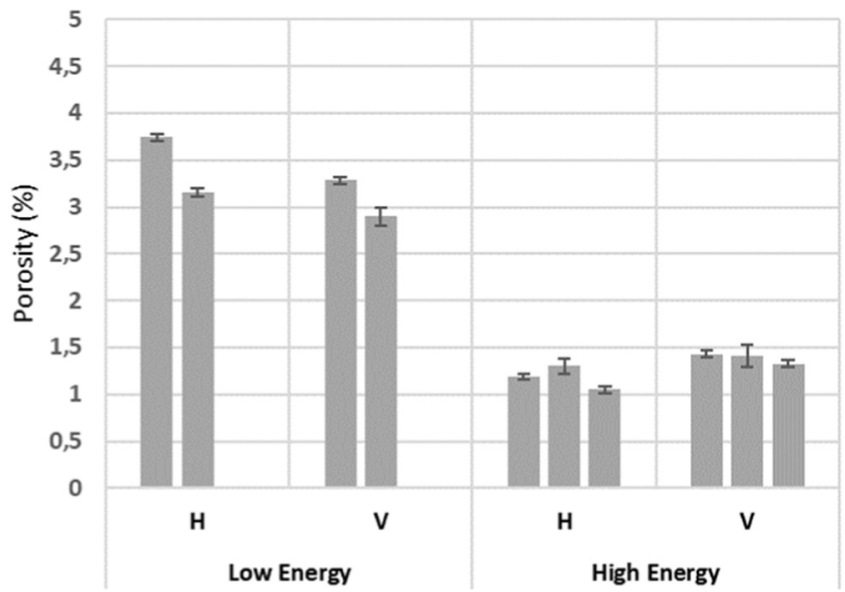

Fig. 4. Porosity rates obtained from L-PBF bars (Archimedes' method). $\mathrm{H}=$ Horizontal building, building angle $\theta=0^{\circ}, \mathrm{V}=$ Vertical building, $\theta=90^{\circ}$ ). Error bars have been estimated over five distinct measurements on each specimen.

with $k_{h}, \alpha, k_{c l}$ and $k_{\text {exc }}$ the loss model coefficients that are usually identified from the experiment. Magnetic characterizations are performed under sinusoidal magnetic flux density.

\subsection{Electrical conductivity measurements}

Regarding the electrical conductivity, the four-point method is employed [23]. In the configuration with a sensor having four aligned needles, a d.c. current $I$ is imposed between the outer pair of needles and a voltage $V$ is measured between the inner needles separated by a distance $\ell$. From the measured resistance, the electrical conductivity $\sigma$ can be deduced. In the present work, the test samples are the bars $\left(5 \times 3 \times 30 \mathrm{~mm}^{3}\right)$ presented in Section 2.2. Electrical conductivity measurements are very sensitive to the physical environment, especially the temperature. Therefore, to guarantee stable conductivity measurements, i.e. less sensitive to temperature fluctuation, all measurements are performed in a temperature chamber controlled at $40{ }^{\circ} \mathrm{C}$ with an homogeneity of $\pm 1{ }^{\circ} \mathrm{C}$.

Rigorously, the 4 point method requires applying a correction factor $F$ that depends on the position of the electrical contact points and shape of the sample:
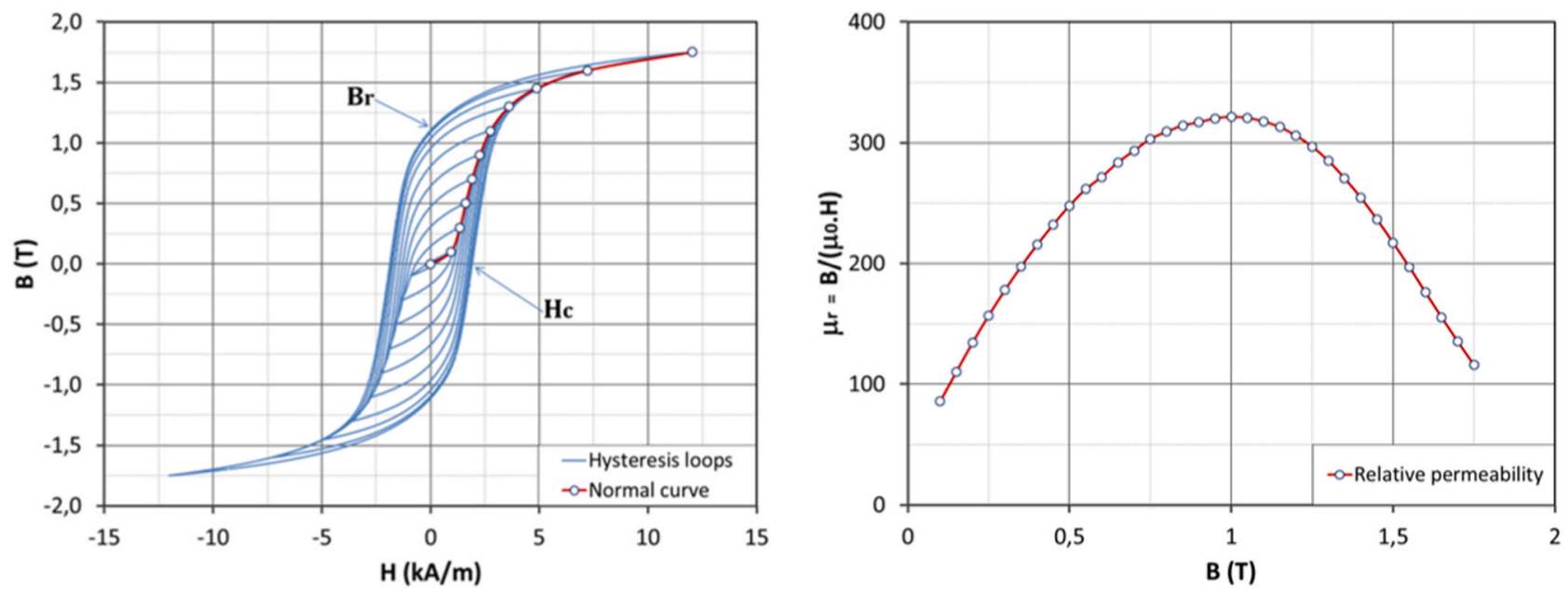

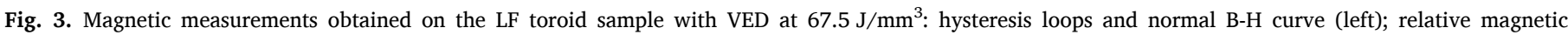
permeability (right). 
$\sigma=\frac{I \ell}{V S} F$

with $S$ the section of the bar crossed by the electrical current. In our case, the correction factor $F$ is determined from an electrokinetic numerical simulation [24] confirming that, for the considered geometry and needle distance, $F \approx 1$.

\section{Results}

\subsection{Estimation of porosity rate}

Porosity rate was estimated with the use of either Archimedes' method (double weighing in air and liquid) or micrographs + image analysis. Archimedes' method results indicate a rather clear tendency: the porosity rate of the bars (see Table 2) manufactured with a low VED $\left(49.6 \mathrm{~J} / \mathrm{mm}^{3}\right)$ and a larger hatch exhibit a much higher porosity $(\sim 3.5 \%)$ than that obtained with the high VED at $67.5 \mathrm{~J} / \mathrm{mm}^{3}(\sim 1.4 \%)$. The reduced overlap between single L-PBF tracks with low VED - large hatch distance logically explains such a difference. More precisely, when VED decreases (low energy condition here below), melt-pool dimensions (depth and width) - dependent on P/V - and overlap - dependent on hatch distance - both decrease, the combination of which provokes lacks-of-fusion.

Micrographs were carried out on cross section of the bars and toroid rings to provide a comparison with density measurement and analyze microstructures. Micrographs were performed on two toroids which were cut into six parts each, for cross section analysis (Fig. 5). This method does not take into account the whole sample but allows to overcome errors from Archimedes' method related to the presence of roughness-dependent air bubbles stuck at the surface, open porosities, and above all to the occurrence of entrapped powder in close porosities which are mostly removed during metallographic preparation. The mean porosity rate measured was $0.15+/-0.05 \%$ for the toroid built with the high VED and of $1.1+/-0.2 \%$ for the low VED - large hatch distance condition.

At low VED (150 W - $720 \mathrm{~mm} / \mathrm{s}$ and a hatch of $140 \mu \mathrm{m})$, most of the porosities exhibit angular contours (Fig. 6) while small spherical porosities are mainly observed at high VED $(175 \mathrm{~W}-720 \mathrm{~mm} / \mathrm{s}$ and a hatch distance of $120 \mu \mathrm{m}$ ). Different physical phenomena explain the different porosity shapes. Spherical pores are formed by gas occlusion unlike pores with angular contours correspond to lacks-of-fusion and come from insufficient tracks overlap at low VED - large hatch distance. The distribution of porosity diameters is shown in Fig. 7. Most of them are below $50 \mu \mathrm{m}$, and small pores $(<10 \mu \mathrm{m})$ are predominant, especially for the high VED condition.

The reason why Archimedes' method (Fig. 4) provided higher porosity rates than micrographs + image analysis may be due to:
(1) a small variation of liquid density with RT which plays a nonnegligible role on data,

(2) the small volume of the samples $\left(0.45 \mathrm{~cm}^{3}\right)$ results in a large specific surface (surface/volume) which enhances the influence of possible wetting issues during sample immersion, especially on high roughness L-PBF surfaces.

(3) a relatively larger porosity rate is usually shown at the L-PBF samples surface, which could explain partially why porosity is higher with Archimedes' method (Fig. 9).

A slight difference between the H-bars and V-bars porosity at high VED (Fig. 4) could be explained by the presence of pores near the overlapping area between the contour and the inskin area (six times more contour contribution with the V-bars). However, this was not confirmed at low VED.

\subsection{Microstructural analysis}

A chemical etching $\left(\mathrm{HCl}, \mathrm{CH}_{3} \mathrm{CO}_{2} \mathrm{H}\right.$, picric acid) was applied on the tilted (T) and flat (F) built toroidal samples to analyze the microstructure and reveal the single L-PBF tracks.

A columnar microstructure is shown, oriented along the build direction $(\mathrm{O}, \mathrm{z})$. Elongated grains, of $180 \pm 70 \mu \mathrm{m}$ length, $40 \pm 10 \mu \mathrm{m}$ width, in the manufacturing direction, can be observed. These columnar grains grow by epitaxy on the grains formed during the previous fusion step (Fig. 8).

Macrographs also confirm a clear inclination of $25^{\circ}$ of the solidification microstructure versus the build direction for the $\mathrm{T}$ toroidal samples. Lacks-of-fusion between adjacent tracks are also clearly confirmed at low VED (Fig. 8, right). The difference observed on the top layers between the $\mathrm{T}$ and $\mathrm{F}$ toroidal samples corresponds to the overlapping fusion area between the upskin and the inskin zone in the case of the T samples (Fig. 10).

At a higher magnification, micrographs indicate a Bainitic to Martensitic structure (Fig. 11), in accordance with CCT diagrams, but further material analysis would be necessary to make a distinction between these two structures. Moreover, no clear difference could be evidenced between high and low VED microstructures. A coarser microstructure was also observed near the L-PBF tracks boundary (Fig. 12).

\subsection{Magnetic properties}

The use of magnetic materials in electro-mechanical energy conversion devices [20] relies on their high magnetic permeability and low iron losses during the energy conversion process. Therefore, it is required to characterize these properties when considering the L-PBF manufacturing process, especially because these properties are dependent on the mechanical and microstructural state of the material.

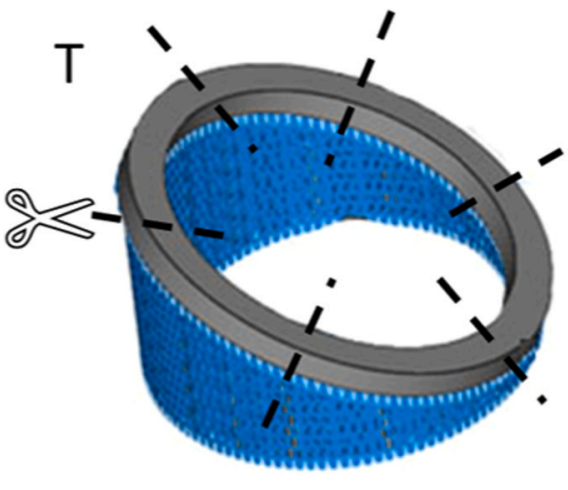

$\mathrm{P}=175 \mathrm{~W} \mathrm{v}=720 \mathrm{~mm} / \mathrm{s} \mathrm{h}=120 \mu \mathrm{m}$

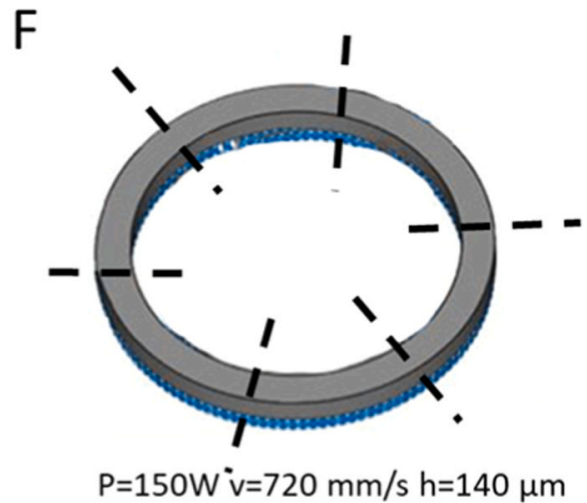

Fig. 5. Scheme of the cut sections of toroids. 

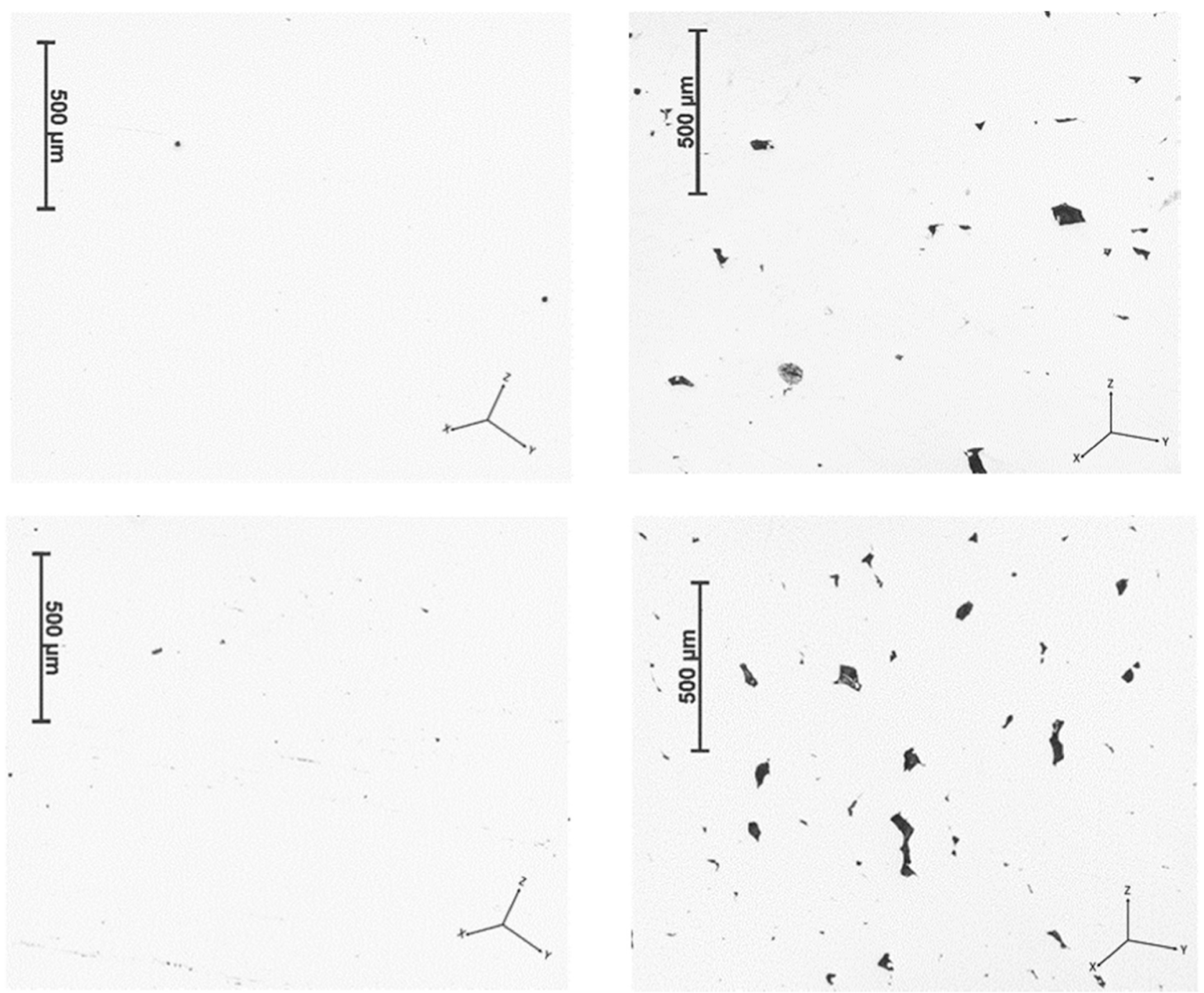

Fig. 6. Micrographic cross-sections of T samples manufactured at high VED on the left ( $\sim 0.15 \%$ porosity) and F samples manufactured at low VED on the right $(\sim 1.1 \%$ porosity) (with $\mathrm{z}=$ building direction), $\mathrm{x} 100$ magnification.

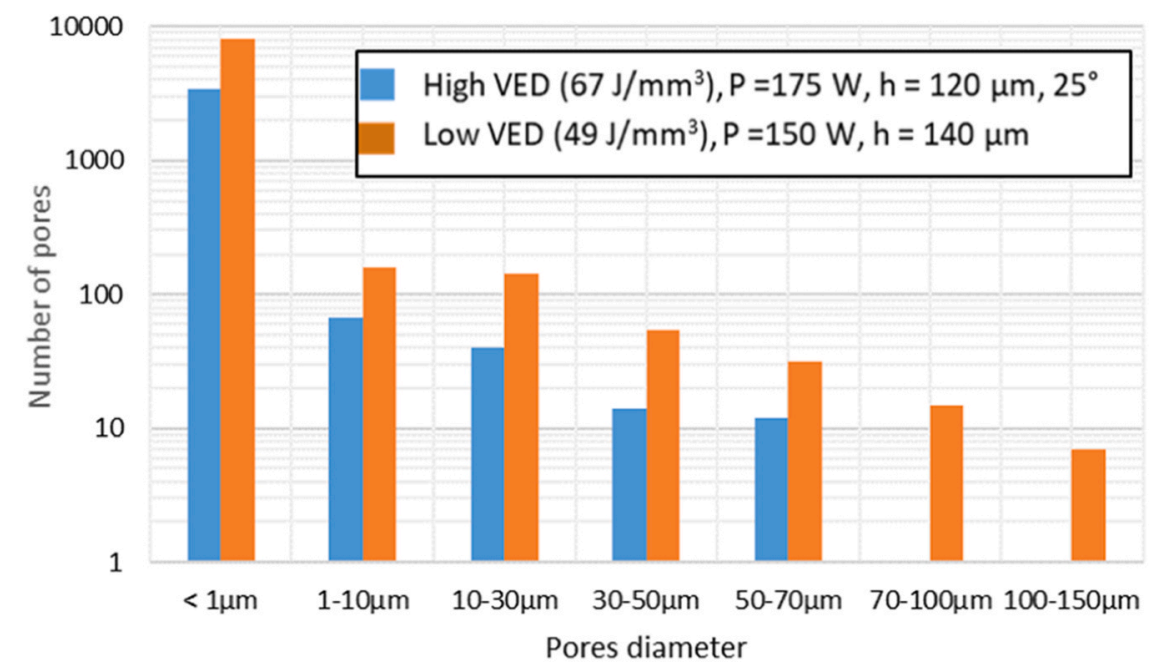

Fig. 7. porosity size distributions (number of counted pores versus pore diameter) obtained from micrographic analysis + image analysis. 
(a)
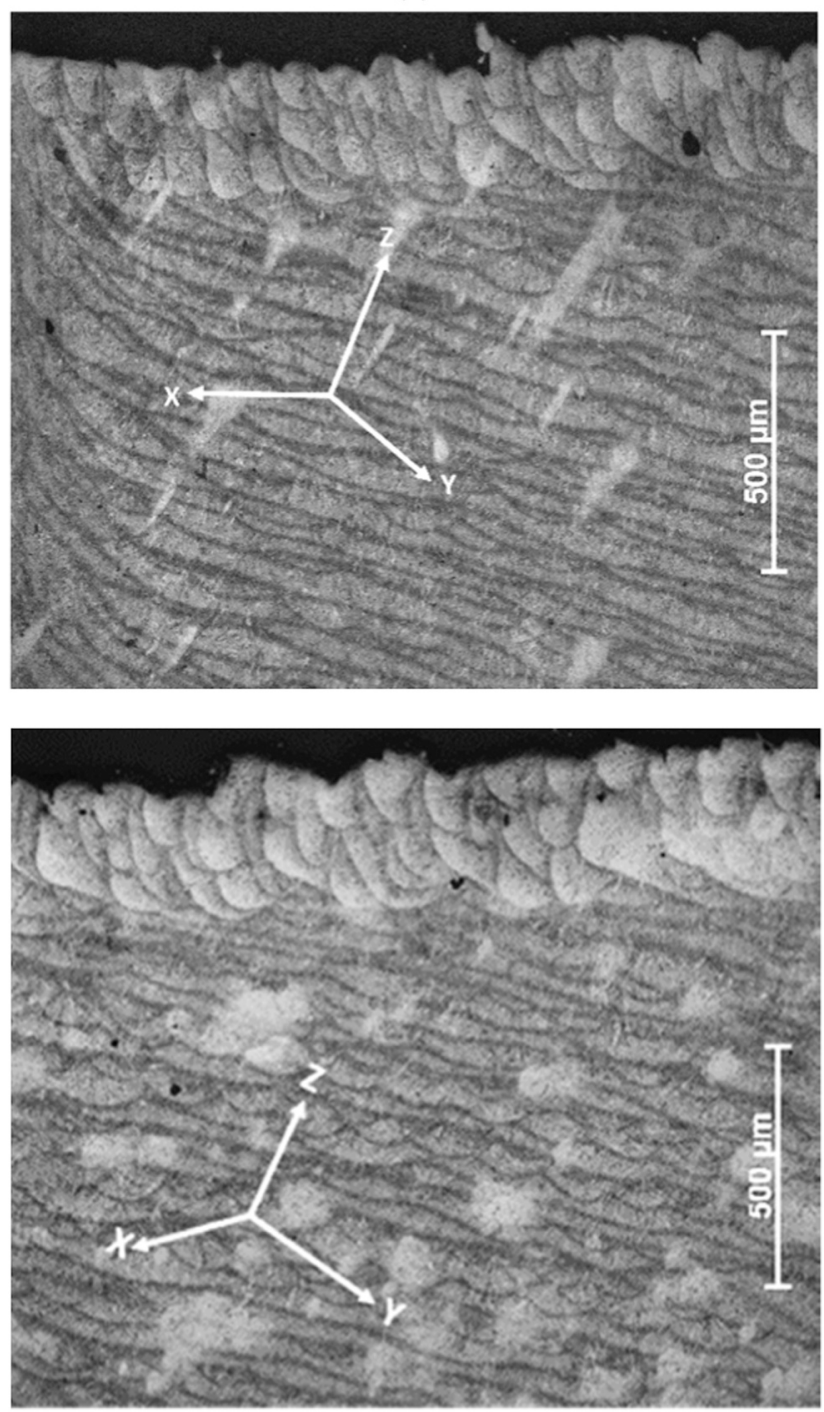

(b)
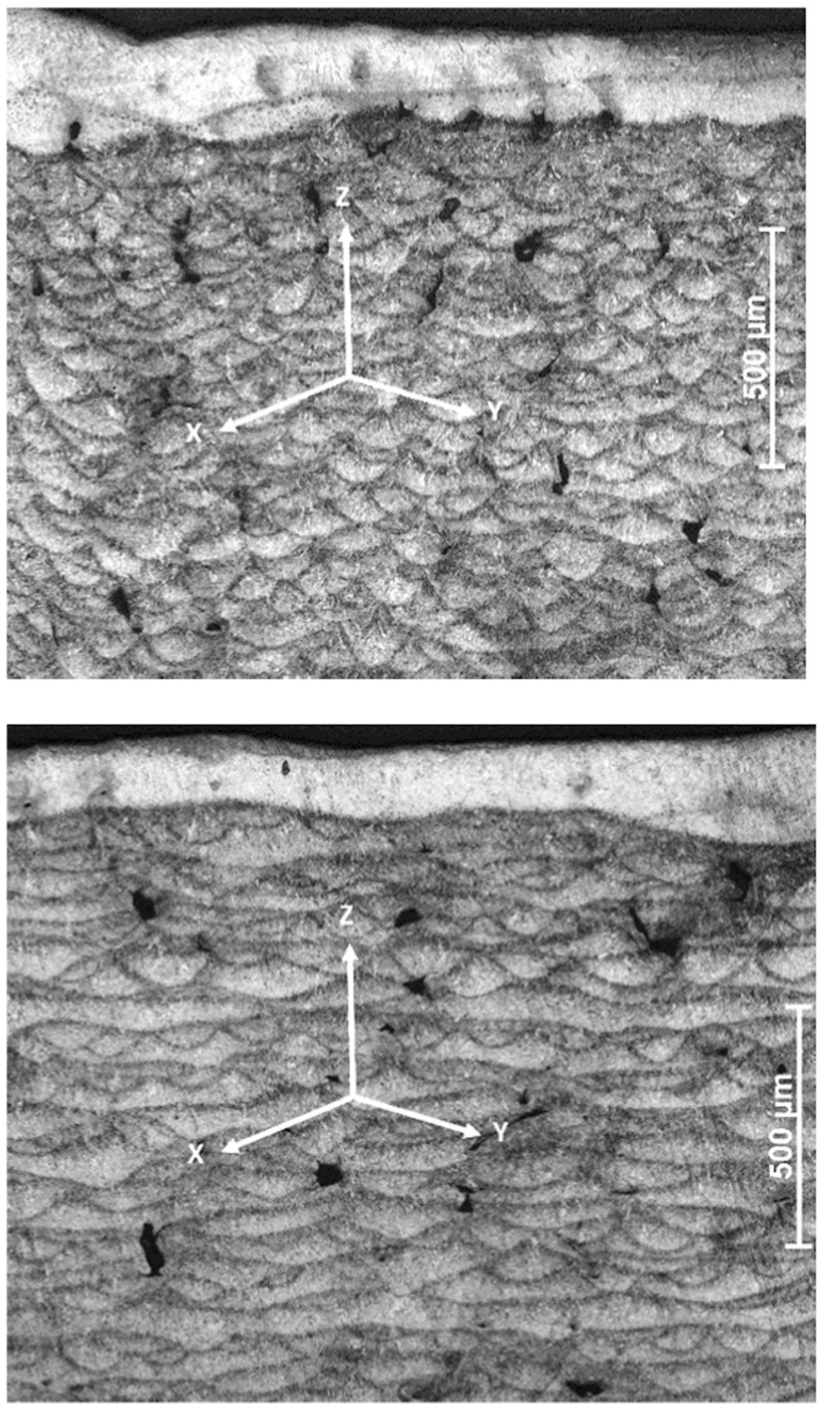

Fig. 8. Macrographs of etched cross-sections for: (a) samples $\mathrm{T}\left(25^{\circ}\right.$ inclined) manufactured at high VED (left column) and (b) samples $\mathrm{F}\left(0^{\circ}\right.$ building angle $=$ parallel to the building platform) manufactured at a low VED (right column) with lacks of fusion (z axis corresponds to the building direction).

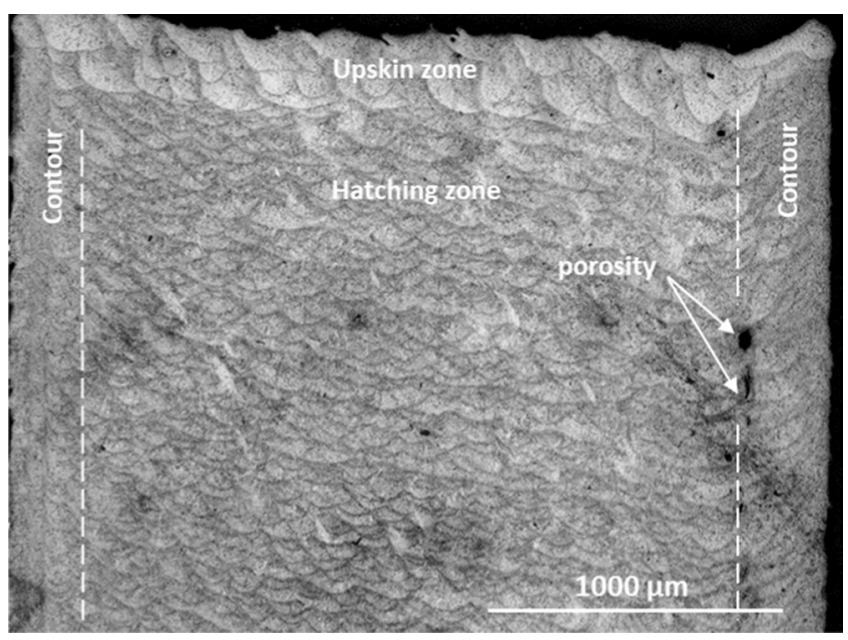

Fig. 9. Macrograph of a samples $\mathrm{T}\left(25^{\circ}\right.$ inclined) manufactured at high VED Occurrence of porosity in the contour-hatching transition zone.
In the following, and given a rather thick cross section of the toroid samples, the magnetic properties have been characterized at the low frequency $10 \mathrm{~Hz}$ for which we expect a limited influence of the dynamic effects due to eddy currents.

\subsection{1. a. Repeatability analysis}

Magnetic properties are sensitive to mechanical and microstructural properties. Therefore a first analysis is conducted to know if there may be variations in the manufacturing process which might or may not influence the magnetic properties. Thus, all toroid samples (see Table 2) have been duplicated with the manufacturing parameters described in Section 2.2.

To evaluate the repeatability error between experimental results of two duplicated toroids (labeled 1 and 2), the relative error is considered such as:

$e r r_{-} r e l=\sqrt{\frac{\int_{0}^{B_{\max }}\left[X_{1}(B)-X_{2}(B)\right]^{2} d B}{\int_{0}^{B_{\max }}\left[X_{1}(B)\right]^{2} d B}}$

where $X(B)$ is for either the B-H curve $H(B)$ or the loss curve $P(B)$.

Overall results obtained for the samples having the same geometries 
Toroid F

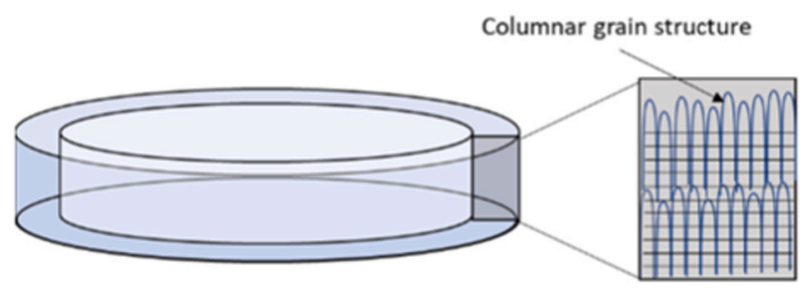

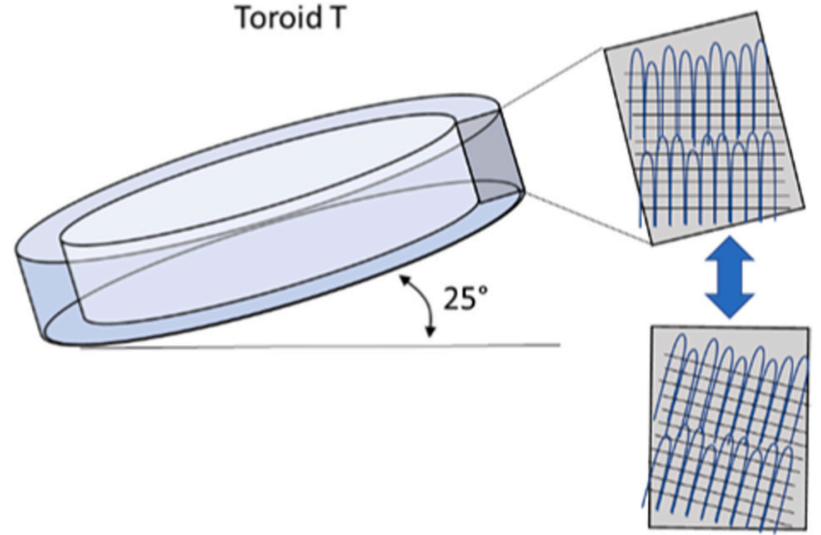

Fig. 10. Microstructure versus toroid orientation.

(a)

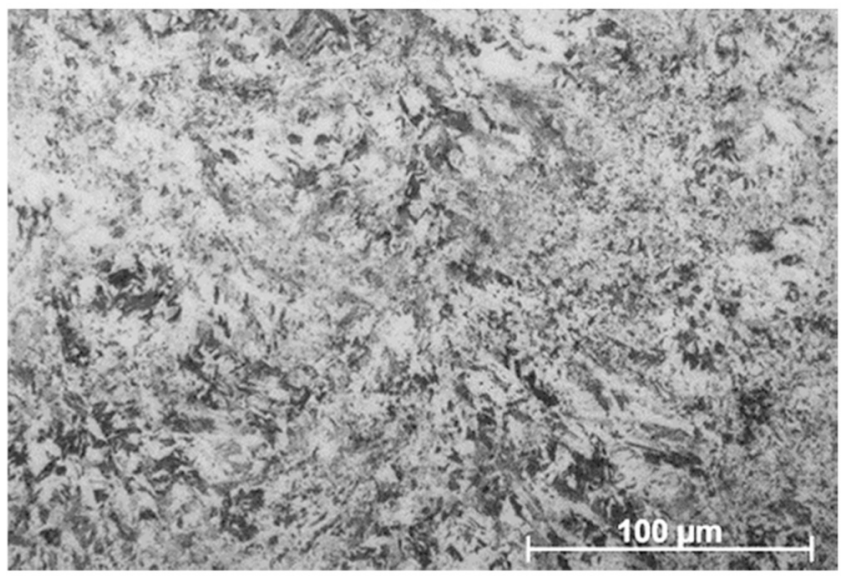

(b)

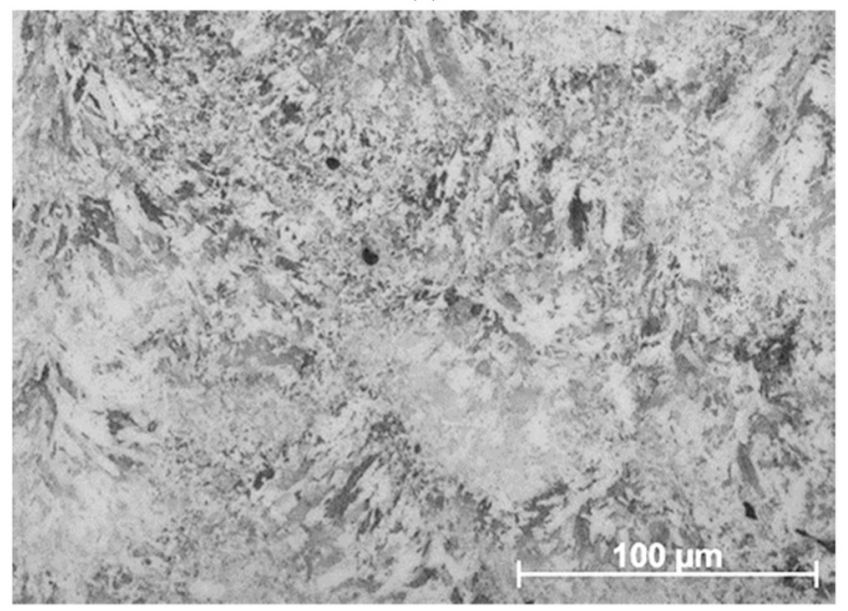

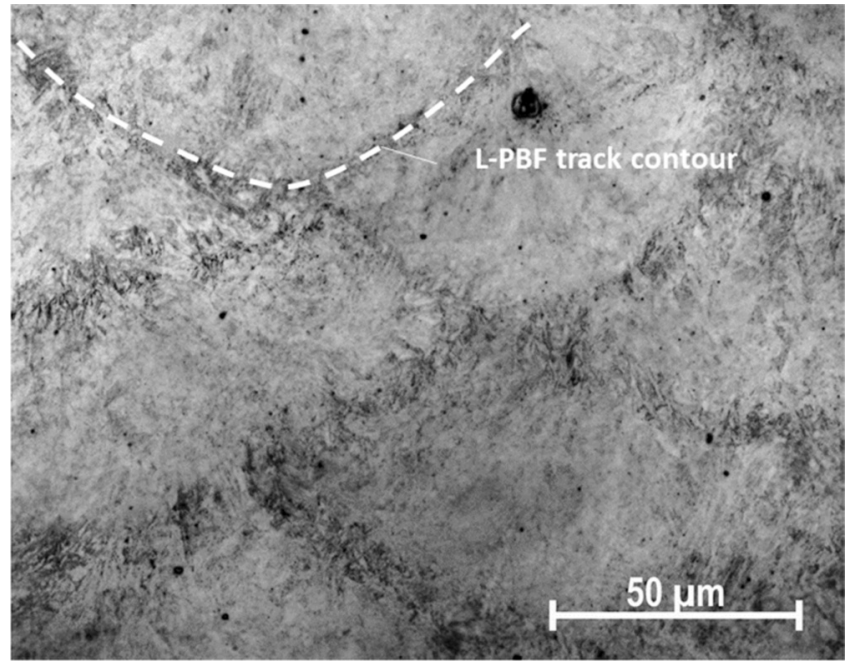

Fig. 12. Local microstructural changes versus tracks' overlaps (Nital $2 \%$ etchant). A coarser microstructure is shown near the track's contour boundaries.

Given these observations, we will consider in the following only one sample per geometry and manufacturing parameters (low and high VED).

\subsection{2. b. Effect of the manufacturing parameters}

The main magnetic property to be analyzed is the $\mathrm{B}-\mathrm{H}$ curve given in Fig. 14 for the small toroid samples (on the left) and for the large ones (on the right).

As a first observation, the manufacturing parameters show a significant impact on the magnetic permeability (which is the slope of the B-H curve). Indeed, we have seen in the previous section that the measurement repeatability is lower than $1.4 \%$. The observed gaps between the B (H) curves in Fig. 14 are more significant and are clearly due to the magnetic material behavior which is different from one sample to another. If we compare the toroids manufactured horizontally (F samples), the high VED configuration (175 W $720 \mathrm{~mm} / \mathrm{s} 120 \mu \mathrm{m})$ gives the Fig. 11. Bainitic-Martensitic microstructure of as-built L-PBF sample for both $\mathrm{s}, \mathrm{h}=120 \mu \mathrm{m}$.

and manufacturing parameters (6 pairs of toroids) lie within a margin of best magnetic performances for both toroid geometries (S and L). This error of $1.4 \%$ for the B-H curves and $1.8 \%$ for the loss curves. This analysis is supported by the porosity characterization in Section 3.1 that demonstrates a very good repeatability of the manufacturing process showed clearly a higher porosity rate for the low VED configuration. regarding the magnetic properties. As illustration, some results are given From the magnetic point of view, the porosities act as a distributed in Fig. 13 in terms of normal B-H curves for two large LT toroid samples airgap within the material, which degrades the global magnetic per( $\mathrm{L}$ for large and $\mathrm{T}$ for the $25^{\circ}$ inclination angle) and also in terms of iron loss curves for two SF toroid samples (S for small and F for flat manufactured samples). formances, especially the B-H curves. Besides, a lower magnetic flux density is observed near saturation for the samples having higher porosity rates due to a lower magnetic volume to be magnetized. In fact, 

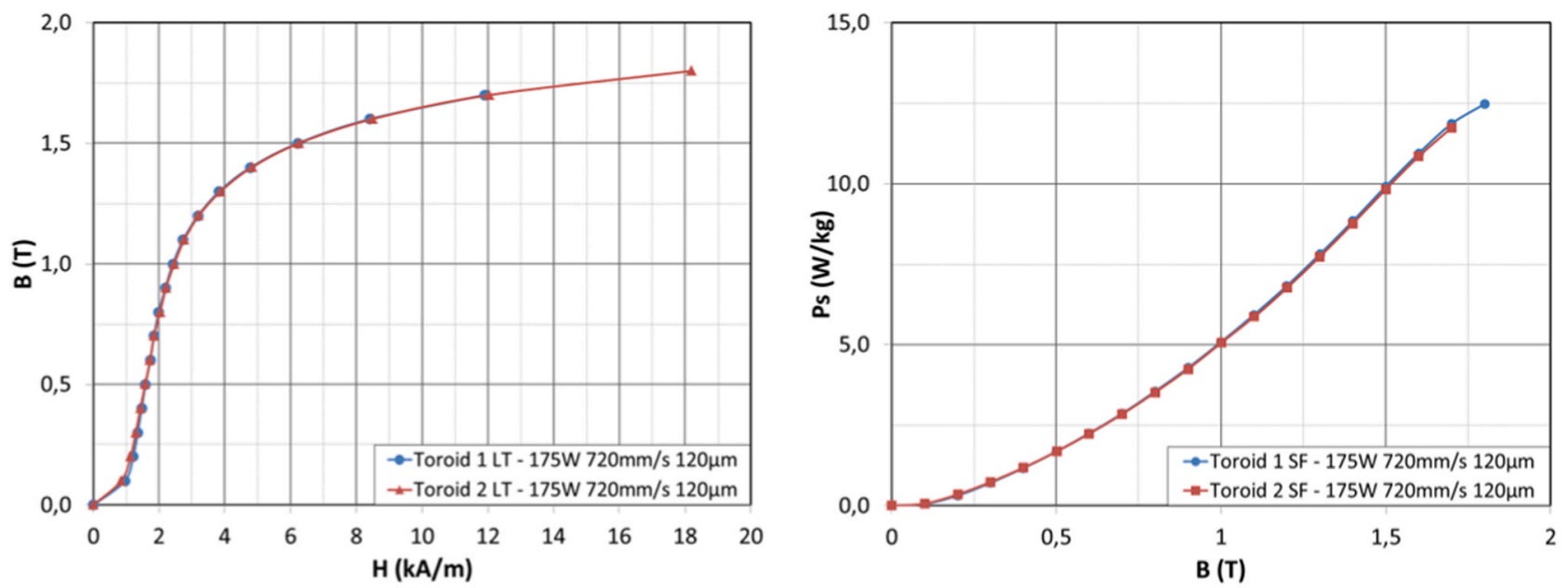

Fig. 13. Repeatability analysis for (left) B-H curves of LT toroid samples and (right) iron loss curves of SF toroid samples, at $\mathrm{f}=10 \mathrm{~Hz}$.
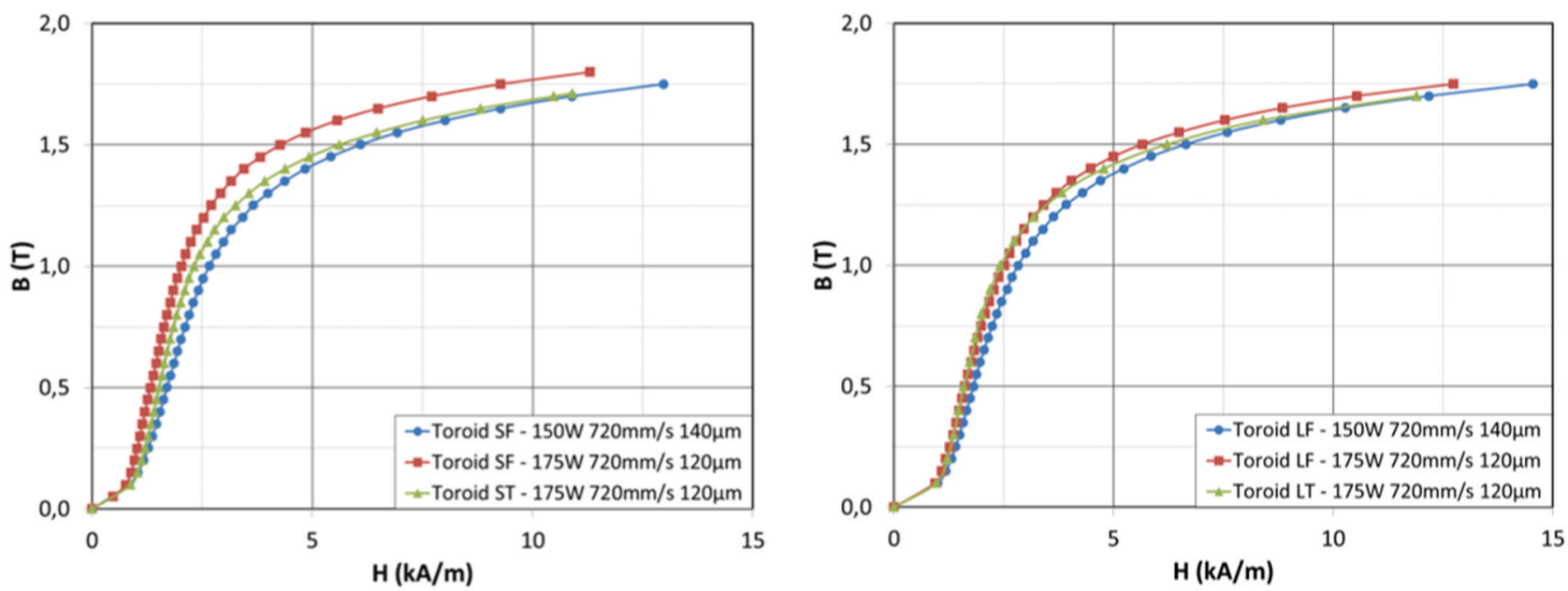

Fig. 14. B-H curves for (left) small toroids samples and (right) large toroid samples at $\mathrm{f}=10 \mathrm{~Hz}$.
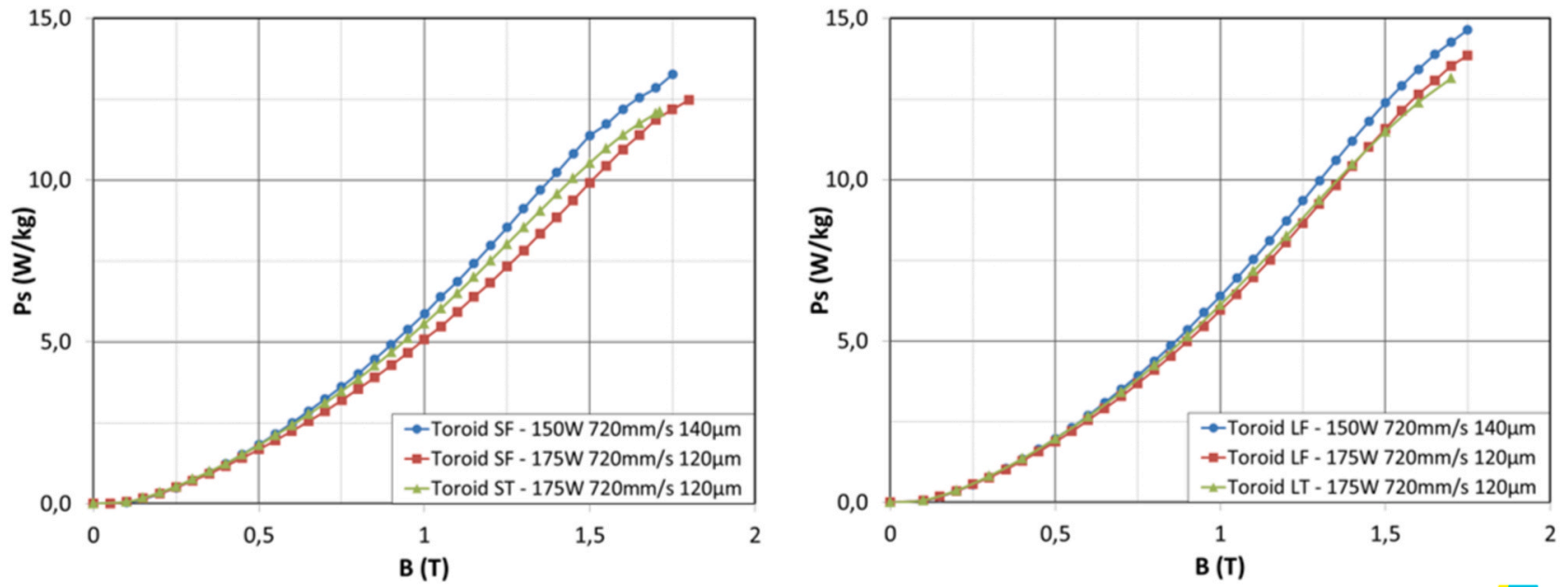

Fig. 15. Iron loss curves for (left) small toroids samples and (right) large toroid samples at $\mathrm{f}=10 \mathrm{~Hz}$. 
the intrinsic magnetic property of the material, the magnetization $M$ defined by (Eq. (9)) and that reflects the number of magnetic moments per unit volume, will also decrease.

$M=\frac{B}{\mu_{0}}-H$

Moreover, when comparing for the same VED (high VED in Fig. 14) the $\mathrm{F}$ toroids manufactured flat with the $\mathrm{T}$ toroids manufactured with a $25^{\circ}$ inclination angle, the magnetic performances are better for the $\mathrm{F}$ toroids. This result is observed for both sample geometries.

When compared to conventional $16 \mathrm{MnCr} 5$, the results from L-PBF $16 \mathrm{MnCr} 5$ are close in terms of magnetization curve. For instance, in [25] the $\mathrm{B}-\mathrm{H}$ curve shows that a magnetic field of about $6 \mathrm{kA} / \mathrm{m}$ is required to reach a magnetic flux density of $1.5 \mathrm{~T}$. In Fig. 14, we observe, for the same magnetic flux density, a magnetic field in the range $4.3-6 \mathrm{kA} / \mathrm{m}$ for the $S$ toroids and in the range $5.6-6.6 \mathrm{kA} / \mathrm{m}$ for the $\mathrm{L}$ toroids. However, our results, especially those of the $S$ toroids, show slightly better magnetic behavior (lower required magnetic field) than the conventional $16 \mathrm{MnCr} 5$ in [25]. Indeed, in this latter reference, the authors considered the magnetic properties from [20] where the steel was employed in an electromagnetic valve and has been through a case-hardening process that is known to be detrimental for the magnetic properties [26].

The evolution of iron losses versus magnetic flux density is reported in Fig. 15. Similar to the B-H curves, we observe that the small toroid samples (on the left) and the large ones (on the right) show the same behavior with regard to the manufacturing parameters. For the F samples, the high VED configuration gives also the best performances with lower iron losses.

However, in the case of large toroids, the LF and LT samples obtained from high VED exhibit very close evolutions of their iron losses, whereas for the small toroids, the ST sample losses are in-between those of SF samples obtained with respectively high and low VED.

The lower performances of the low VED samples in terms of losses are also linked to the porosity rate that is higher in that case as observed in Section 3.1. In practice, for the same global magnetic flux density (associated to the cross section of the toroid), the low VED samples will exhibit a higher effective magnetization within the material volume (porosities are not magnetic) and iron losses will increase as predicted by (Eq. (6)). Also, the angular contours of the lack-of-fusion porosities, observed for the low VED samples, suggest high local stress concentrations that are expected to degrade the magnetic properties.

A global observation for the previously presented magnetic results is related to the difference of behavior between the $S$ and $L$ samples for the

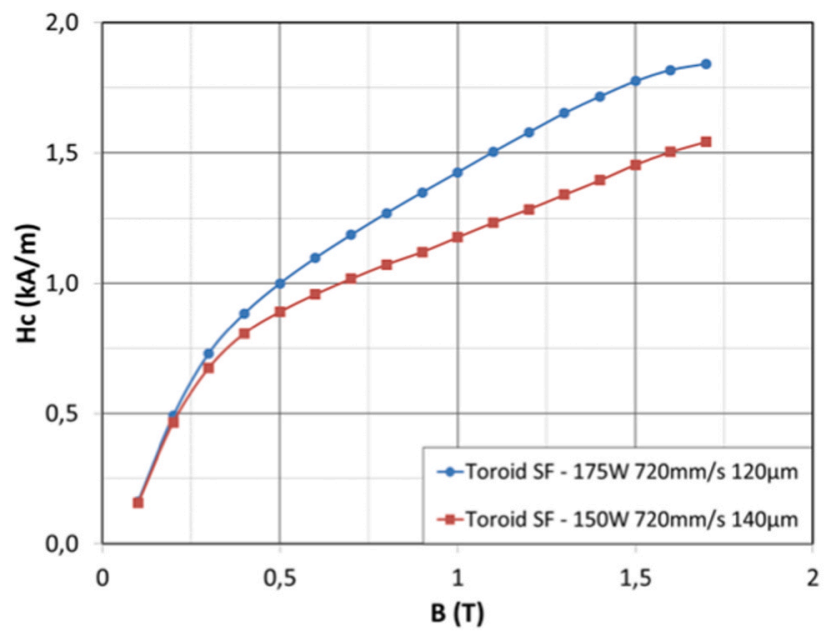

same manufacturing parameters. The $S$ samples always show better magnetic performances in terms of B-H curves and iron losses. In fact, at the considered excitation frequency $(10 \mathrm{~Hz})$, the dynamic effects, especially classical eddy currents, can explain this difference. To further analyze and support this hypothesis, a loss decomposition approach has been carried out in the following section.

To synthetize the effect of manufacturing parameters on the magnetic properties, Fig. 16 reports the evolutions of the coercive field (left) and relative magnetic permeability (right) for the SF samples obtained from high and low VED. These data are extracted from the hysteresis loops as explained in Section 2.4. The coercive field evolution is obviously consistent with the evolution of the iron losses (Fig. 15): higher coercive field yields higher iron losses. As mentioned earlier for the low VED samples, the angular contours of the lack-of-fusion porosities suggest high local stress concentrations. Mechanical stress is known to degrade the magnetic properties, especially the coercive field that will increase [27]. Regarding the relative permeability evolution, this latter is also consistent with the B-H curves presented in Fig. 14 that show lower magnetic properties for low VED samples.

\subsection{3. c. Analysis of the toroid geometry factor}

The B-H and loss curve evolutions between SF and LF toroids are emphasized in Fig. 17 for the low VED configuration. As previously mentioned, the dynamic effects, due to classical eddy currents in different thicknesses of toroids ( $3 \mathrm{~mm}$ for $\mathrm{S}$ samples and $5 \mathrm{~mm}$ for $\mathrm{L}$ samples), are suspected to lead to these different behaviors.

Starting from (Eq. (6)), the hysteresis losses can be extracted from the evolution of the specific energy $P_{\text {tot }} / f$ versus the frequency:

$\frac{P_{t o t}}{f}=k_{h} B_{\text {max }}^{\alpha}+k_{c l} f B_{\text {max }}^{2}+k_{\text {exc }} f^{1 / 2} B_{\text {max }}^{3 / 2}$

To have a good estimation of the hysteresis losses, the extrapolation of the specific energy to "zero" frequency requires additional data at lower frequencies. In Fig. 18, the specific energy is reported versus the frequency for a peak magnetic flux density of $1 \mathrm{~T}$, for both the SF and LF samples manufactured at low VED. The typical behavior described by (Eq. (10)) is observed for the whole range of frequency up to $260 \mathrm{~Hz}$. A zoom at the low frequency region shows that the specific energy tends towards the same value for zero frequency. Therefore, it can be concluded that the quasi-static loss term is similar for both toroid geometries. This observation is made for all other $\mathrm{S}$ and $\mathrm{L}$ toroids having the same manufacturing parameters.

Finally, it can be assumed that the loss difference observed at higher frequencies for toroid rings built with the same L-PBF parameters, is mainly due to dynamic effects, especially the classical eddy current

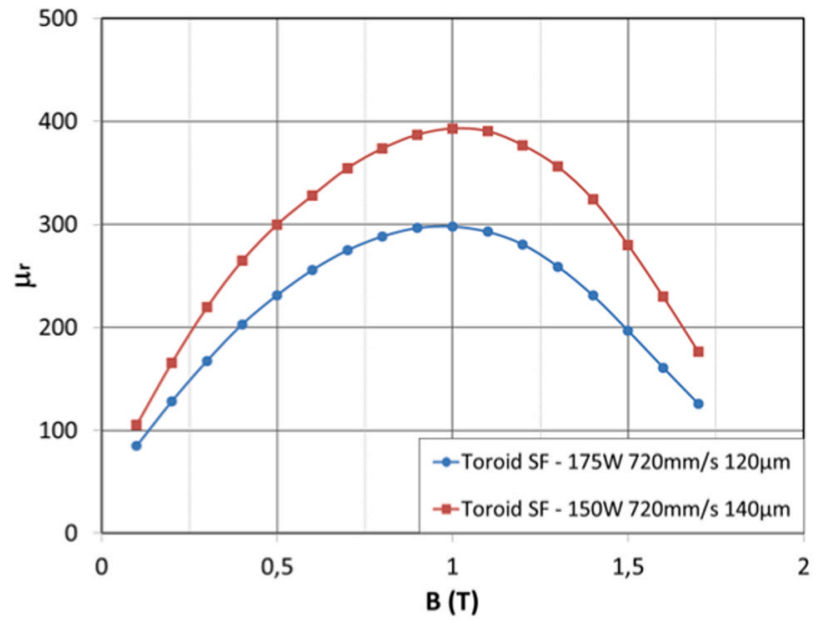

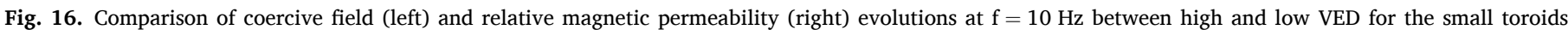
build flat. 

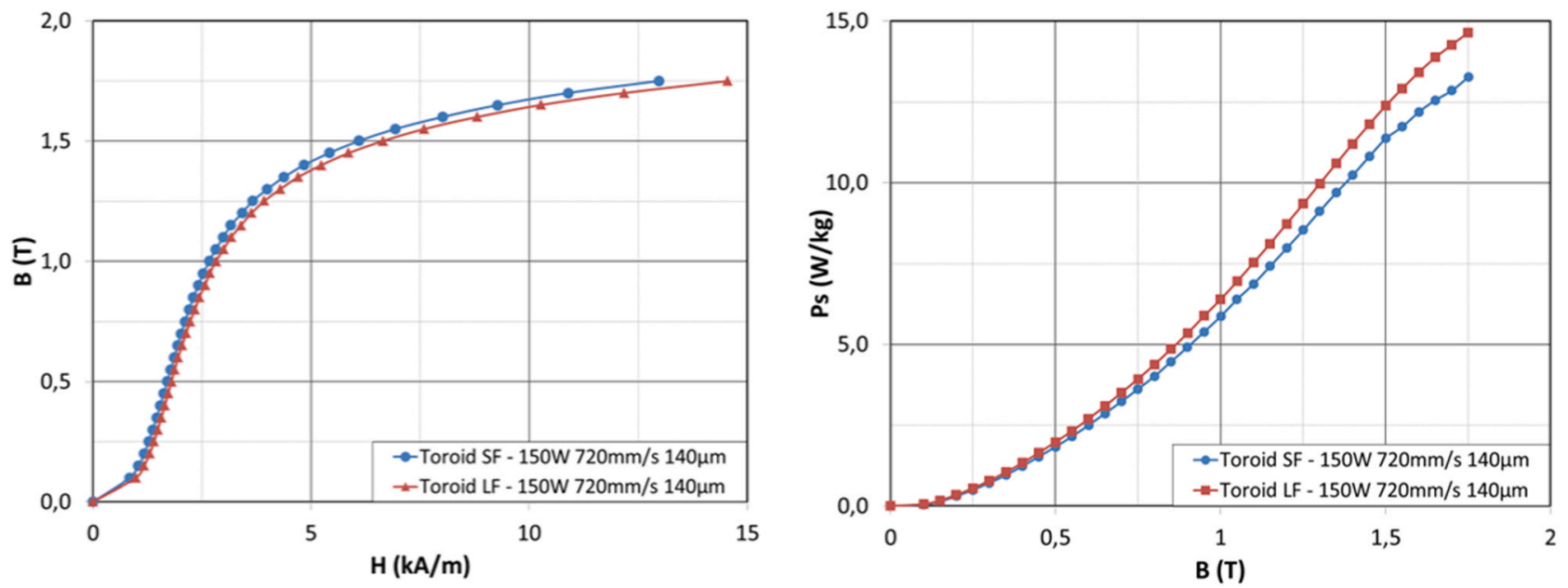

Fig. 17. Comparison of B-H curve and iron loss evolutions between small and large toroids manufactured with the same parameters (low VED) at $\mathrm{f}=10 \mathrm{~Hz}$.

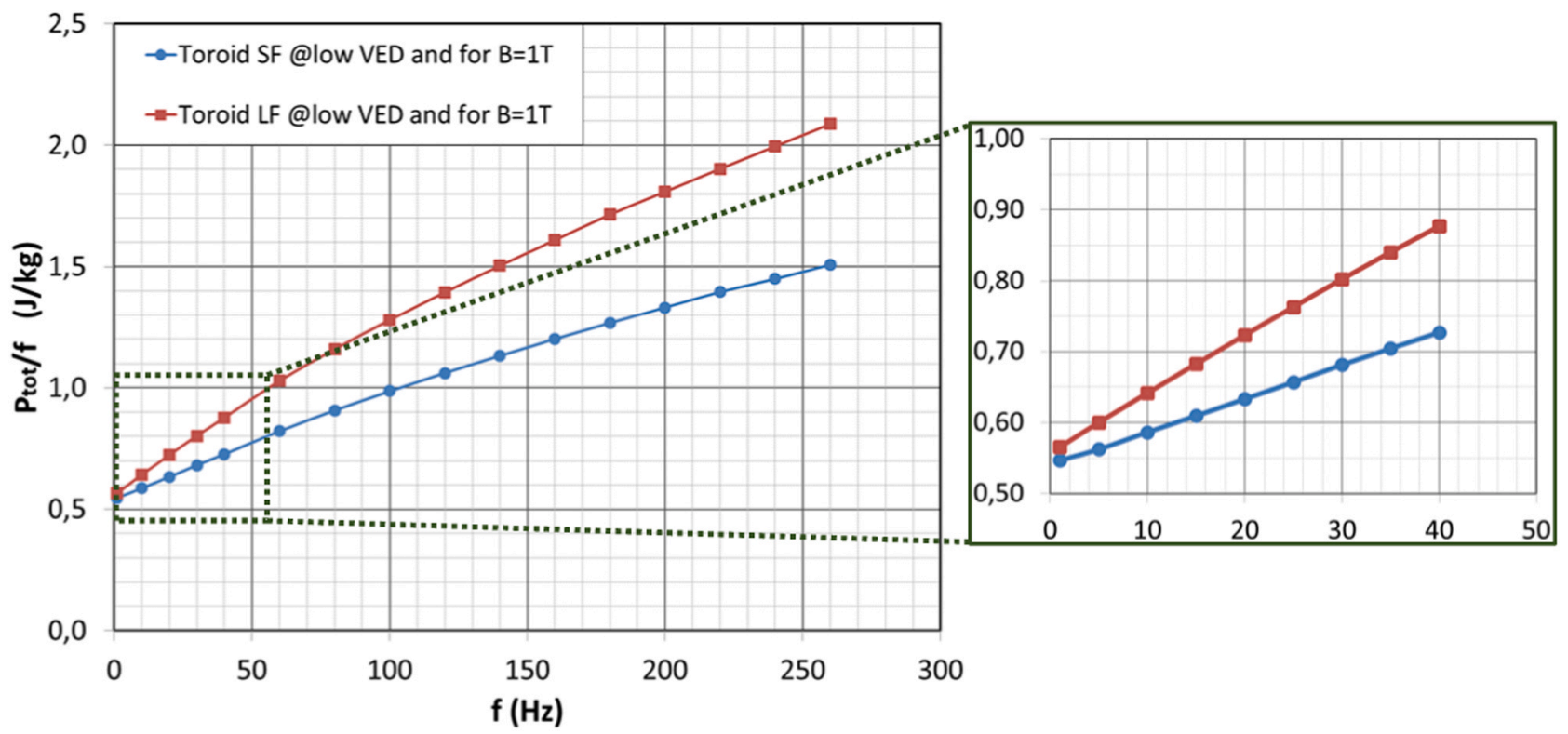

Fig. 18. Extrapolation of specific energy to "zero" frequency for both toroid geometries.
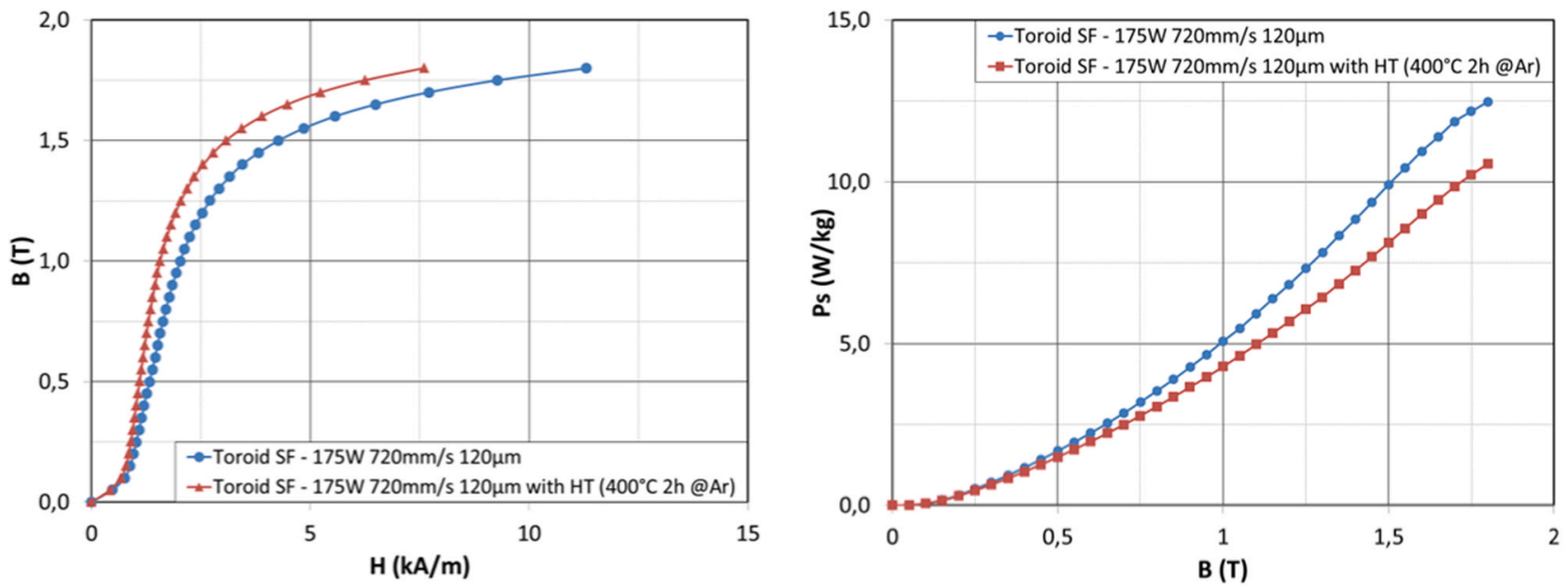

Fig. 19. Comparison of B-H curve and iron loss evolutions (at $\mathrm{f}=10 \mathrm{~Hz}$ ) before and after heat treatment $\left(400{ }^{\circ} \mathrm{C} 2 \mathrm{~h} @ \mathrm{Ar}\right)$ for a SF sample manufactured with high VED. 
losses.

The same explanation is behind the small difference in terms of B-H curve, shown in Fig. 17. In fact, eddy currents tend to attenuate the magnetic flux density B. Consequently, to obtain the same magnetic flux density in both toroids, the magnetic field $\mathrm{H}$ should be higher for the $\mathrm{L}$ sample than for the $\mathrm{S}$ sample where the eddy current effect is the lowest.

\subsection{4. d. Heat treatment effect}

The L-PBF process may introduce residual stresses [28]. Therefore, knowing that residual stresses are likely to degrade the magnetic properties, a tempering heat treatment has been considered for stress relief in the sample exhibiting the best magnetic performances, i.e. the SF sample built with high VED. In $[18,19]$ the stress relief heat treatment for $16 \mathrm{MnCr} 5$ has been performed at $650^{\circ} \mathrm{C}$ for $6 \mathrm{~h}$. However, these studies also reported recrystallization and grain refinement after the heat treatment. In the present work, to avoid potential recrystallization that would also have an effect, in addition to the already mentioned stress relief effect, on the magnetic properties, we chose a lower temperature for the heat treatment. This latter was performed with a heating rate of $40{ }^{\circ} \mathrm{C} / \mathrm{min}$, a $2 \mathrm{~h}$ time maintain at $400{ }^{\circ} \mathrm{C}$ under argon atmosphere, and a air-cooling.

Results of magnetic characterization after the thermal treatment are given in Fig. 19. A significant improvement of the magnetic properties, for both the B-H curve and iron losses, is observed. For example, at $1.8 \mathrm{~T}$, the required magnetic field is decreased by $33 \%$ and the losses are decreased by $15 \%$. This noticeable result suggests to consider, after the $\mathrm{L}-\mathrm{PBF}$ process, a heat treatment procedure of pieces designed for magnetic applications.

\subsection{Electrical conductivity}

The electrical conductivity of a material is determined by its composition but also by other material characteristics, such as the porosity, the density of dislocations, the precipitates and the crystal structure that will also influence the ability for electrons to move within the material. Therefore, it is of interest to characterize the electrical conductivity with regard to the manufacturing process parameters that have an influence on the microstructure of the material.

The average electrical conductivity obtained for 4 manufacturing process parameters (combining low/high VED with horizontal/vertical sample position) is reported in Fig. 20. First, the obtained values are in the expected range $4-6 \mathrm{MS} / \mathrm{m}$ for the $16 \mathrm{MnCr} 5$ material grade as reported by different manufacturers [29] for a casted steel. Moreover, the low VED samples exhibit a slightly lower electrical conductivity $(\sim 3.95$ $\mathrm{MS} / \mathrm{m})$ than the high VED condition $(\sim 4.1 \mathrm{MS} / \mathrm{m})$. The lower electrical conductivity $(-5 \%)$ may be explained by the higher porosity rate that consequently induces a lower sectional area for the electrical current. However, for a given VED, the sample building direction does not have any significant influence on the electrical conductivity.

\section{Conclusions}

The present study was focused on $16 \mathrm{MnCr} 5$ samples built with L-PBF additive manufacturing technique in order to investigate as-built microstructures and resulting magnetic and electric properties. Various manufacturing process conditions were considered, including the influence of volume energy density (VED), hatch distance and inclination angle, and built part size. Two levels of porosity rates were obtained for the two different series: near $1.1 \%$ for the low VED - large hatch, and near $0.15 \%$ for the high VED - small hatch distance, with a low influence of build angle. The large porosity rate of $1.1 \%$ was mainly attributed to lacks-of-fusion due to insufficient re-melting of adjacent tracks.

Regarding the magnetic properties, we observed an increase of the iron losses and a degradation of the normal B-H curve (decrease of magnetic permeability) with: (a) low VED and high porosity rate (lacksof-fusion), (b) the inclination of built parts, (c) the size of toroid rings,

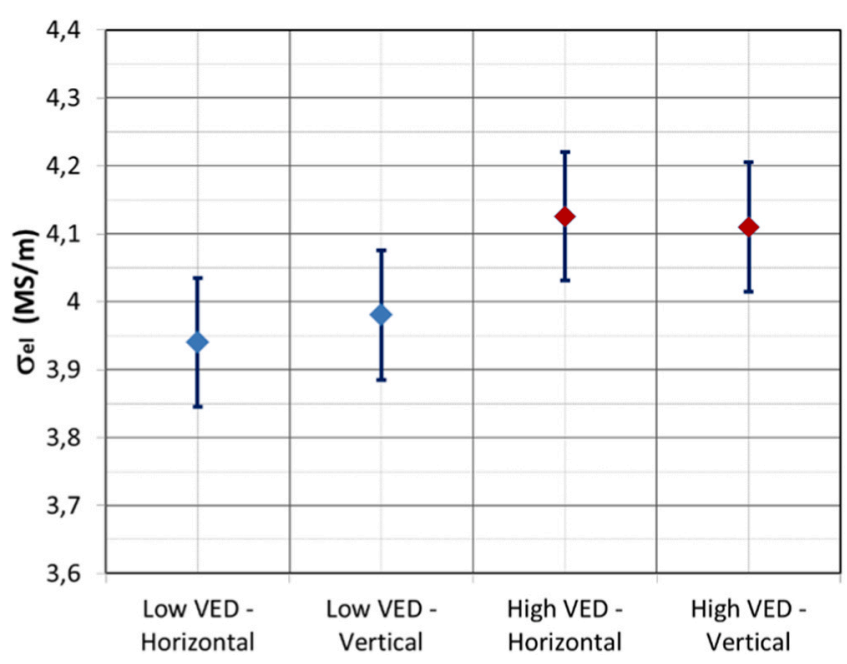

Fig. 20. Average electrical conductivity at $40{ }^{\circ} \mathrm{C}$ for different L-PBF configurations.

whereas electrical conductivity seems to be only dependent on the porosity.

Finally, the influence of a low temperature stress relief was also demonstrated, with a clear improvement of magnetic properties after heat treatment. However, additional investigation is still needed to optimize the heat treatment for recovering optimal magnetic properties.

\section{CRediT authorship contribution statement}

C. Dupuy: Conceptualization and design of study, Acquisition of data, Drafting the manuscript, Approval of the version of the manuscript to be published (the names of all authors must be listed); A. Benabou: Conceptualization and design of study, Acquisition of data, Analysis and/or interpretation of data, Drafting the manuscript, revising the manuscript critically for important intellectual content, Approval of the version of the manuscript to be published (the names of all authors must be listed); S. Shihab: Acquisition of data, Analysis and/or interpretation of data, Approval of the version of the manuscript to be published (the names of all authors must be listed); O. Messal: Acquisition of data, Analysis and/or interpretation of data, revising the manuscript critically for important intellectual content, Approval of the version of the manuscript to be published (the names of all authors must be listed); $\mathbf{S}$. Clénet: Conceptualization and design of study, Drafting the manuscript, revising the manuscript critically for important intellectual content, Approval of the version of the manuscript to be published (the names of all authors must be listed); P. Peyre: Conceptualization and design of study, Analysis and/or interpretation of data, Drafting the manuscript, revising the manuscript critically for important intellectual content, Approval of the version of the manuscript to be published (the names of all authors must be listed).

\section{Declaration of Competing Interest}

The authors declare that they have no known competing financial interests or personal relationships that could have appeared to influence the work reported in this paper.

\section{References}

[1] K. Bartsch, J. Ohrenberg, C. Emmelmann, Benchmark parts for the evaluation of optimized support structures in Laser Powder Bed Fusion of metals, 11th CIRP Conference on Photonic Technologies [LANE 2020] on September 7-10, 2020.

[2] G. Strano, L. Hao, R.M. Everson, K.E. Evans, Surface roughness analysis, modelling and prediction in selective laser melting, J. Mater. Process. Technol. 213 (4) (2013) 589-597. 
[3] O. Andreau, I. Koutiri, P. Peyre, J.D. Penot, N. Saintier, E. Pessard, T. De Terris, C. Dupuy, T. Baudin, Texture control of 316L parts by modulation of the melt pool morphology in selective laser melting, J. Mater. Process. Technol. 264 (2019) 21-31.

[4] B. Zhang, N. Fenineche, H. Liao, C. Coddet, Magnetic properties of in-situ synthesized FeNi3 by selective laser melting Fe-30\%Ni powders, J. Magn. Magn. Mater. 336 (Suppl C) (2013) 49-54.

[5] F. Yan, W. Xiong, E.J. Faierson, Grain structure control of additively manufactured metallic materials, Materials 10 (2017) 1260.

[6] A. Kreitcberg, V. Brailovski, S. Turenne, Effect of heat treatment and hot isostatic pressing on the microstructure and mechanical properties of Inconel 625 alloy processed by laser powder bed fusion, Mater. Sci. Eng. A 689 (2017) 1-10.

[7] W.E. Frazier, Metal additive manufacturing: a review, J. Mater. Eng. Perform. 23 (6) (2014) 1917-1928.

[8] W. Everhart, J. Newkirk, Grain size effects in selective laser melted Fe-Co-2V, Appl. Sci. 9 (2019) 3701.

[9] R. Hilzinger, W. Rodewald. Magnetic materials: Fundamentals, Products, Properties, Applications, Wiley, 2013 (ISBN 978-3-895-78352-4).

[10] T. Riipinen, S. Metsä-Kortelainen, T. Lindroos, J. Sami Keränen, A. Manninen, J. Pippuri-Mäkeläinen, Properties of soft magnetic Fe-CoV alloy produced by laser powder bed fusion, Rapid Prototyp. J. 25 (2019) 699-707. ISSN: 1355-2546.

[11] M. Yakout, M.A. Elbestawi, L. Wang, R. Muizelaar, Selective laser melting of soft magnetic alloys for automotive applications, Joint Special Interest Group meeting between Euspen and ASPE Advancing Precision in Additive Manufacturing, Ecole Centrale de Nantes, France, (2019).

[12] B. Li, W. Fu, H. Xu, B. Qian, F. Xuan, Additively manufactured Ni-15Fe-5Mo Permalloy via selective laser melting and subsequent annealing for magnetic shielding structures: process, microstructural and soft-magnetic characteristics, J. Magn. Magn. Mater. 494 (2020), 165754.

[13] M. Garibaldi, I. Ashcroft, J. Lemke, M. Simonelli, R. Hague, Effect of annealing on the microstructure and magnetic properties of soft magnetic Fe-Si produced via laser additive manufacturing, Scr. Mater. 142 (2018) 121-125.

[14] M. Garibaldi, I. Ashcroft, N. Hillier, S. Harmon, R. Hague, Relationship between laser energy input, microstructures and magnetic properties of selective laser melted Fe-6.9\%wt Si soft magnets, Mater. Charact. 143 (2018) 144-151.

[15] D. Goll, D. Schuller, G. Martinek, T. Kunert, J. Schurr, C. Sinz, T. Schubert, T. Bernthaler, H. Riegel, G. Schneider, Additive manufacturing of soft magnetic materials and components, Addit. Manuf. 27 (2019) 428-439.
[16] A. Plotkowski, J. Pries, F. List, P. Nandwana, B. Stump, K. Carver, R.R. Dehoff, Influence of scan pattern and geometry on the microstructure and soft-magnetic performance of additively manufactured Fe-Si, Addit. Manuf. 29 (2019), 100781.

[17] M. Schmitt, G. Schlick, C. Seidel, G. Reinhardt, Examination of the processability of $16 \mathrm{MnCr} 5$ by means of laser powder bed fusion, 10th CIRP Conference on Photonic Technologies (LANE 2018), Procedia CIRP, 74 (2018), 76-81.

[18] M. Schmitt, T. Kamps, F. Siglmüller, J. Winkler, G. Schlick, C. Seidel, T. Tobie, K. Stahl, G. Reinhart, Laser-based powder bed fusion of $16 \mathrm{MnCr} 5$ and resulting material properties, Addit. Manuf. 35 (2020), 101372, https://doi.org/10.1016/j. addma.2020.101372.

[19] D. Bartels, J. Klaffki, I. Pitz, C. Merklein, F. Kostrewa, M. Schmidt, Investigation on the case-hardening behavior of additively manufactured $16 \mathrm{MnCr} 5$, Metals 10 (4) (2020) 536, https://doi.org/10.3390/met10040536.

[20] J. Zhao, L. Fan, P. Liu, L. Grekhov, X. Ma, E. Song, Investigation on electromagnetic models of high-speed solenoid valve for common rail injector, Math. Probl. Eng. 2017 (2017) 1-10, https://doi.org/10.1155/2017/9078598.

[21] IEC 60404-4, Magnetic materials - Part 4: Methods of measurement of d.c. magnetic properties of magnetically soft materials, (2008).

[22] G. Bertotti, General properties of power losses in soft ferromagnetic material, IEEE Trans. Mag. 24 (1) (1988) 621-630.

[23] F.M. Smits, Measurement of sheet resistivities with the four-point probe, Bell Syst. Tech. J. 37 (3) (1958) 711-718.

[24] M. Jamil, A. Benabou, S. Clénet, L. Arbenz, J.C. Mipo, Development and validation of an electrical and magnetic characterization device for massive parallelepiped specimen, Int. J. Appl. Electromagn. Mech. 61 (S1) (2019) S1-S8.

[25] J. Zhao, S.E. Zirka, Y.I. Moroz, T. Matsuo, Physical Cauer circuits in nonlinear eddy-current modeling, J. Magn. Magn. Mater. 508 (2020), 166850, https://doi. org/10.1016/j.jmmm.2020.166850.

[26] J. Logan and J. Taylor, The magnetic properties of a case-hardened steel and their effect on the performance of an electromagnetic actuator, SAE Technical Paper 900265, (1990). https://doi.org/10.4271/900265.

[27] O. Stupakov, J. Pal'a, I. Tomáš, J. Bydžovský, V. Novák, Investigation of magnetic response to plastic deformation of low-carbon steel, Mater. Sci. Eng. A 462 (1-2) (2007) 351-354.

[28] M. Shiomi, K. Osakada, K. Nakamura, T. Yamashita, F. Abe, Residual stress within metallic model made by selective laser melting process, CIRP Ann. Manuf. Technol. 53 (1) (2004) 195-198.

[29] 16MnCr5 data sheet from OVAKO Company, (2020). https://steelnavigator.ovako. com/steel-grades/16mncr5/. (Accessed 09 September 2020). 